\title{
Urbanized Life
}

\author{
John Zerzan
}

"It is odd, after seventy centuries of city life, that we continue to be uneasy about it and uncertain as to what is wrong."

About twenty years ago I left the San Francisco Bay area to move back to my native Oregon. A paramount factor was how very little radical activity could be seen among so many people. I should also add that there wasn't much going on anywhere at that point, compared to the ' 60 s movements and to what has since developed in some places beginning in the late ' 90 s.

But there's something about cities that militates against resistance, at least against explicitly anarchist resistance. (I'm not talking here about such important areas as urban movements for racial justice, for example.) Whatever happened to the city as a site of utopian contestation? What about the Situationists' dreams for cities of the future? They advocated the practice of dérive (drift), aimlessly encountering and savoring the surprises that an urban landscape could provide. Guy Debord described what happened to Paris in the '70s, its uglification and tragic decline.

How much character exists in American cities? They are progressively cheapened, standardized zones, like the rest of manufactured life. Of course, there are still some districts that are relatively more interesting or more affordable than others...one step ahead of an accelerating rate of gentrification. By and large, enclaves of livability are doomed, along with those other cultural remnants, bohemia and the avant-garde.

Cultural activities are often cited as an important reason to live an urban life. Yet the city voraciously devours time and energy, according to Sahlins' law: the more culture is available, the more work is being performed. Thus, the search for quality is being steadfastly defeated, especially in cities.

Marshall Sahlins' anthropological perspective can also be usefully applied to contemporary anti-authoritarian politics. His dictum helps explain why big cities are not the chief loci of resistance or autonomy. Marx was wrong in seeing "enormous cities" as sites of growing opposition, places where workers would feel "that strength more" (1848).

In the 1960s in the United States, college towns like Berkeley, Ann Arbor, Madison, and Kent were at the forefront of the radical movement_ not the big cities. Take a look at the situation today, with respect to fresh ideas. The cutting edge periodicals of the new movement originate in towns like Eugene, Oregon (Green Anarchy); Greensburg, Pennsylvania (Species Traitor); and Columbia, Missouri (Anarchy). Anarchist zines published in, say, Detroit (Fifth Estate) and Baltimore (Social Anarchism) are unoriginal and nonradical. I'm sure there are exceptions, but in general not much is happening in the cities.

Undeniably, authentic struggles (and inspired outbursts, like Black Bloc actions) take place in cities. Yet the urban milieu appears to be entrapped by failed and superficial perspectives. The post-left horizon, insistent on more deeply radical insights and aims, is feeble or invisible in the city.

What is the city? What are its defining institutions? Some are interested in such questions; others consider them unimportant. People who are still defined by the left tend not to look deeply at their own circumstances; they actively defend urban existence.

This is the age of the megalopolis, the era of a world system dictated by its world-cities. The cancerous reach of the outspread cities masters everything that is nonurban. This expansionism embodies the soullessness of the Machine in its unconditional mastery of the land, its severance from nature. The city-spirit is a symptom of civilization's malignancy, and deserves our full attention as an obstacle within our milieu. 
Globalization is urbanization, with half the planet's population already in the cities, and over 75 percent to be city dwellers by 2050. The mega-cities already incarnate a universal, sterile sameness, reminiscent of airports, supersized hotels, and cruise ships: Destination Nowhere. The urban civilization that encompasses the globe advertises its deadly traits for all to see.

The word civilization derives from Latin roots meaning "culture of cities." As with civilization, in the city every basic urban feature has been present from the beginning. As Lewis Mumford wrote (1961), "By the time the city comes plainly into view it is already old."

As with civilization, division of labor is among the city's most fundamental institutions. Melinda Zeder (1991) describes the dynamic: "With increased specialization activities also become more hierarchical.... Thus, the urban landscape becomes a direct reflection of the degree of specialization and hierarchy in society—a mirror of state complexity." Anarchists of the left, who have no desire to question or abolish division of labor, speak of "abolishing the state" while remaining ignorant of one of its cardinal wellsprings. The state arises from productive specialization, the need to coordinate both specialization and production, and the power of some people over others demanded by these arrangements.

Priests and leaders quickly take control of a central political administration, with a monopoly of force that is the constant warrant against the autonomy of its subjects/citizens. Similarly what was once a reciprocal, person-toperson exchange of nonessentials becomes stratified, politically directed trade in permanent, central places: cities. And because they are artificially created places that can't exist without trade, the new forms of exchange must be guaranteed. Hence armies, and war. Fortified cities are as old as cities themselves.

Urbanization has many other civilizational attributes, negatively related to the physical environment, gender relations, and personal health, for example. Their reproduction depends, in the last analysis, on the refusal to identify, indict, and combat them at their source.

In a recent interview, Michael Hardt and Tony Negri (authors of Empire, 2000) offer their excuses for this refusal: "We and our world are thoroughly artificial, or, rather, there is no longer a way to differentiate between what is artificial and what is natural. Abandoning the notion of nature means, once again, refusing any possible pretence of purity and accepting our corrupted and contaminated state."

Here leftists and postmodernists (among others) join hands to celebrate their collaboration with the dominant order. They accept the subjugation and even the extinction of nature just as it would never occur to them to question urban life, the very offspring of those destructive forces. The city was and remains a defeat that must be undone. 